\title{
Study on the Prevention and Controlling of Dissimilation of Social Functions of Commercial Banks Based on the Fulfillment of Social Responsibility of Chinese Commercial Banks
}

\section{Zhuobi Luo}

School of Marxism, Central University of Finance and Economics, Beijing 100081, China Email: cufelzb@163.com

\begin{abstract}
The dissimilation of the social functions of commercial banks is a phenomenon that the function of commercial banks deviates from the economic development and the people's livelihood. Such phenomenon, which can be seen all over the world, impedes the socio-economic development and affects the well-being of the people to some degree. After investigating and analyzing the dissimilation of the social functions of Chinese commercial banks, it was found that their social functions play a significant role, and the booming development of these banks has made great contribution to the economic growth and improved people's livelihood in China. China should also have special experience in preventing and handling this dissimilation.
\end{abstract}

Keywords: commercial bank, social functions, dissimilation, experience

\section{Introduction}

A commercial bank is a type of bank that accepts various types of deposits from the public and then makes business loans to different sectors. So it makes money by providing loans, earning interest income from those loans, investment and commissions by third-party through the intermediary function of credit and payment. It has become an important actor for maintaining economic prosperity and stability and promoting social harmonious development by continuously sending financial capital to all fields in the community. The proper fulfillment of social functions of commercial banks plays a significant role in politics, economy, culture, society and even ecology. On the contrary, it will affect the stability of social and economic order and people's life well-being. Influenced by different political systems and social values, the alienation of social functions of commercial banks is widespread in the world. Since the reform and opening up, China has made full use of the advantages of socialist political system and culture, and has taken a road to the development of commercial banks with Chinese characteristics.

\section{Functions and dissimilation of commercial banks}

\subsection{Functions of commercial banks}

From a legal perspective, a commercial bank is a legally established business entity to accept deposits from the public, make loans, offer checking account services and other services. From the academic point of view, the commercial bank is a profit-based comprehensive and multi-functional financial institution, with the main business of financial assets and liabilities. As an important intermediary in the social economy and finance, commercial banks are not only the enterprises that operate independently, bear their own risks, assume sole responsibility for its profits or losses, exercise self-restraint and bear civil liabilities independently with all their corporate properties, but also the institutions that play an important role in the allocation of resources in the national economy, through the main businesses of financial assets and liabilities, by regulating the most important resource of the market economy - currency and providing services to the public, organizations and countries with its special intermediary function of currency and credit. ${ }^{[1]}$ Generally speaking, commercial banks have five social functions: regulating economy, credit creation, credit intermediary, payment intermediary and financial service.

\subsection{Dissimilation of the functions of commercial banks}

Dissimilation originally means separation and estrangement. Hegel interprets alienation as the division and opposition between subject and object. Marxism argues that dissimilation, produced together with the class, is a kind of dissident forces that comes from the material and spiritual production of people and, in turn, rules the human. It is the process by which the forces which are separated from man become alienated from himself, and in turn become the forces which 
control and dominate him. The division of labor under the condition of private ownership is the source of dissimilation. Dissimilation shows the phenomenon that people's productive activities and their products are in turn against themselves. ${ }^{[2]}$ In this process, human's subjectivity and initiative do not work any more and they are enslaved by different forces (such as capital). In addition, human's personality can not be fully developed, which results in one-sided or even distorted development.

The dissimilation of social functions of commercial banks is the phenomenon and tendency of commercial banks deviating from their own social functions, social value, the needs of economic development and people's well-being. Commercial banks blindly pursue monetary appreciation, deviate from the real economy and keep increasing liabilities, which contributes to financial bubbles and increased financial risks. The loans, which are made for doing someone a favor or made because someone pulls strings, increase the non-performing loan rate, affecting the security and development of commercial banks. The profit-driven commercial banks also do not pay enough attention to sound development, causing problems concerning resources and environment. Moreover, customers and regional discrimination in commercial banks leads to the unfair financial social services, and widens the gap between the rich and the poor.

As intermediaries of capital, commercial banks are essentially mercenary for the capital controlled by themselves, and seek profit by various means. Without strict regulation and supervision of capital flow, it is easy to go astray and bring out the worst in itself. As the center of national economic activities, commercial banks are the hubs of monetary capital, and they inject the energy into national economic development. Without being fettered by morality, the guidance and supervision of the government are easy to be dominated by capital, resulting in dissimilation and systematic risk. Since the commercial banks are considered as the core of economy and finance, the dissimilation of their social functions will definitely contribute to higher financial risks, hinder the sound development of the national economy and affect the wellbeing of the community.

\subsection{Discussion on the dissimilation of commercial banks from the perspective of avoiding the real and seeking the virtual capital}

Investment and financing activities are the main businesses of commercial banks. However, the blindly profit-driven activities will easily lead to financial bubbles, resulting in the deviation of flowing of bank capital from the real economy. This will not only lead to higher financial risks, but also cause damage to the environment of the real economy. In the real estate market in China's first-tier cities, for example, the growth rate of housing prices in big cities such as Beijing, Shanghai, Guangzhou and Shenzhen exceeds over 15\% from 2007 to 2017, much faster than the growth rate of residents' income. ${ }^{[3]}$

This can have an impact on the real economy in, at least, two aspects. First, it has reduced the consumption of the real economy. Because of high housing prices, people have to use most of their income to pay off debts. The overdrafts are their consumption in the future, which reduces their purchasing power, makes social products can not be bought, resulting in overproduction. In addition, the land rent for the real economy is rising, which has a great impact on the real economy. Second, it hinders the flow of capital into the the real economy.

In order to maintain and increase the value of the capital, people make the capital flow to the "prosperous" real estate market, forming the vicious circle of money from the individuals, institutions and entity enterprises used for property speculation speculating. This will lead to the enterprise financialization and produce the crowding-out effect on the real economy. The real economy can not get effective financial support, which will affect the innovation and transformation of enterprises and ultimately undermine the sustainable development of the real economy. If the problems of depression of real economy, and economic bubbles can not be resolved in time and effectively, it will definitely lead to higher systematic financial risks and even economic and financial crisis. So the commercial banks that pursue capital appreciation will not only disrupt the normal social and economic order, but also have a deficit or even to go bankrupt.

\subsection{Discussion on the dissimilation of commercial banks from the perspective of the capital making people lose subjectivity}

A commercial bank is an economic organization approved by the state according to the need of social development. As the fruit of human development, it serves people, and is also controlled and organized by people. However, more and more people are now controlled by bank capital. As consumers, people are enslaved by mortgage loan, housing loan, car loan, consumption loans; as practitioners, they are controlled by capital issues such as how capital increases in value and how capital can be used to generate higher profits; as bank shareholders, due to the stock-ownership diversification, one identity of shareholder (social man) is lost under the profit-oriented system in which economic man always behaves 
rationally. Under this background, more people realize that the subjectivity of human being is gradually replaced by the subjectivity of capital, which tends to become the power to rule everything. In the capital market, the capital is used for both earnings and excess earnings. Whether the capital appreciation method and the process are legitimate or conform to relevant laws, regulations and professional ethics is unimportant or even may be ignored. Marxism argued that capital is better understood as a social relation than as a thing from the perspective of the capital appreciation, and pointed out that the capital is a kind of compulsory right which comes from the dominant position of society through the "relations". In this regard, scholar Wang Bo said that when capital develops into monetary capital and productive capital, the characteristic of capital - thing - seems to disappear, and another characteristic - social relation - emerges, and capital begins to control the material production in the community. In this connection, accumulated, past and materialized labor becomes the primary factors to control the direct and living labor. The capital of dead labor begins to control man and living labor. Capital puts all human relations under its control and manipulates all these human relations. ${ }^{[4]}$ This is an inverted relationship between subjectivity and objectivity, showing the social relation of capital. Capital, which is created by man, begins to, in turn, dominate man, make man lose his subjectivity, and becomes the power to rule everything, and gradually establishes the false subjectivity by and with itself. The false subjectivity of capital results in dissimilation and is the cause of dissimilation of social functions of commercial banks.

\section{Performance of social functions of Chinese commercial banks}

In order to develop a better understanding of the social functions of Chinese commercial banks, the study focuses on the fulfillment of the social responsibility of Chinese commercial banks and a survey was conducted to practitioners in the field and ordinary people. From 2018 to 2019, 393 questionnaires from bank practitioners and data from 2,799 people were collected in 29 provinces across the country. In addition, the data concerning oversight released by supervision department of Bank of China in recent years and the data of social responsibility disclosed by Chinese listed companies were collated.

The data shows that $66.9 \%$ of the public think that Chinese commercial banks pay enough attention to social morality, and $85.2 \%$ think that the impact of Chinese commercial banks on the national economy is positive or at least neutral, $62.2 \%$ think that serving the people is reflected in the services provided by these banks and $67.3 \%$ think that the socialist core values can also be reflected in the activities of banks.

The data shows that $65.39 \%$ of the practitioners believe that the booming development of China's commercial banks contributes to the economic growth, and $64.89 \%$ believed that banks play a positive role in helping the poor and improving people's livelihood, and $82.69 \%$ of them consider that commercial banks have paid attention to saving resources and protecting the environment, and $75.07 \%$ consider that banks attach importance to the code of ethical conduct and play an exemplary role in social ethics, and $77.86 \%$ think that serving the people is reflected in the services provided by banks and $82.19 \%$ argue that the socialist core values can also be reflected in the activities of banks.

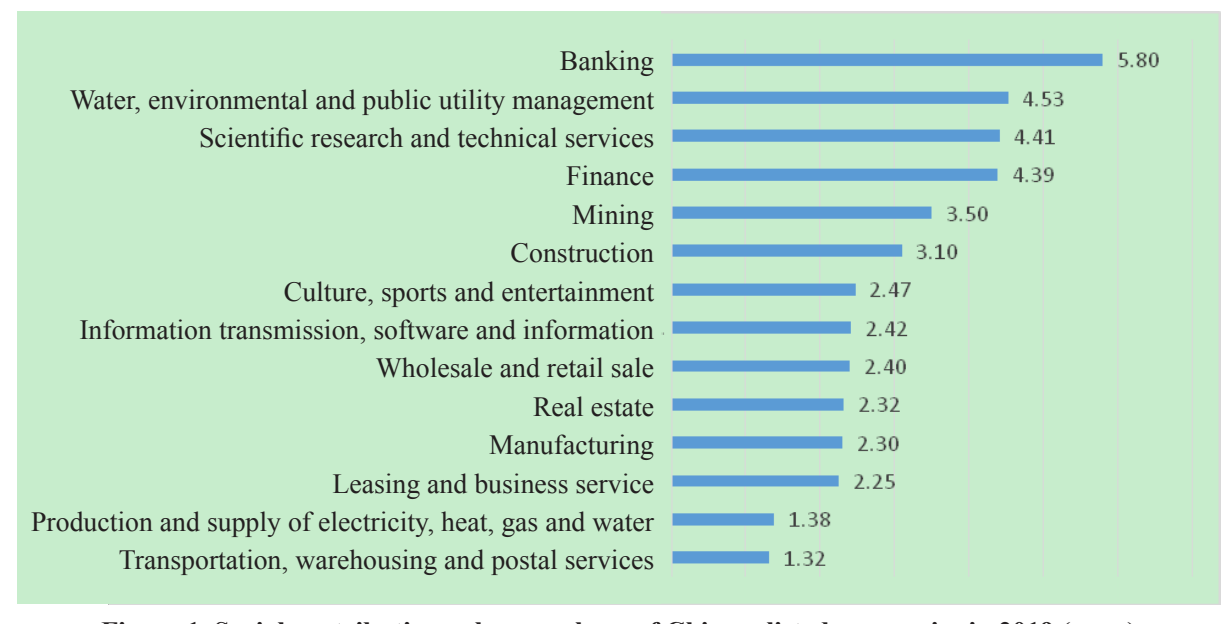

Figure 1. Social contribution value per share of Chinese listed companies in 2019 (yuan) (Source: Data disclosed by social responsibility reports of listed companies)

After collating the data disclosed by social responsibility reports of listed companies, it can be found that the social contribution value per share of Chinese listed commercial banks in 2019 was 5.80 yuan on average, greater than 4.39 yuan in the financial sector and 3.04 yuan in other sectors (see Figure 1). The social contribution value per share is the ratio of the total social contribution created by the company to the company's share capital. It is calculated by deducting the costs, 
for instance, caused by the company due to environmental pollution from the earnings per share and the amount of value created by the company for the state, employees, creditors, communities and other stakeholders during the year.

In this study, data were collected from 3,372 administrative penalty cases disclosed by the China Banking Regulatory Commission (CBRC) and its 36 regulatory branches from January 2016 to December 2019, including 88 administrative penalty cases by the CBRC and 3,284 cases of administrative penalty imposed by the regulatory branches. ${ }^{[5]}$ Moreover, 2,036 fines were imposed on institutions, 969 fines imposed on individuals, and 279 fines imposed on both institutions and individuals. The total fine was 4.205 billion yuan, of which 29.469 million yuan from individuals. From the basis according to which administrative punishment is given, the number of punishment for non-compliance in credit business is the largest, up to 1,593 cases and accounting for 49.84\%; the number of punishment in bill business is the second only to credit business, up to 421 cases and accounting for $13.17 \%$; there were 669 cases, accounting for $21 \%$, punished for violating the principle of acting cautiously in management. In terms of the number and amount of fines, the supervision on China's commercial banks has always been strengthened.

On the whole, social functions of China's commercial banks are essential, and these banks also try their best to fulfill their social responsibilities. Their booming development has made tremendous contributions to the economic growth and the livelihood of the people. Their business activities demonstrate the socialist morality and value system with Chinese characteristics. Moreover, they perform more social functions than the listed companies, and the Chinese government keeps strengthening oversight on their fulfillment of social responsibilities.

\section{Prevention and handling experience of dissimilation of social functions of Chinese commercial banks}

The survey data show that China's commercial banks play a significant role in performing their social functions. China is also one of the major economies in the world that has not experienced an economic or financial crisis in decades. It can be seen that the government have done a great job in preventing and handling the dissimilation of social functions of Chinese commercial banks. Under the socialism with Chinese characteristics, the dissimilation, which can be found in commercial banks across the globe, has been solved in China in four ways as follows:

\subsection{Management of banks is seen as a priority on the national agenda}

China's major commercial banks, including the Industrial and Commercial Bank of China, the Agricultural Bank of China, the Bank of China, the China Construction Bank, the Bank of Communications and the Postal Savings Bank of China, are all state owned commercial banks. More than 80 percent of the assets of commercial banks are owned or controlled by the government. As commercial banks become more important in the community, the Chinese government has put the governance of social functions of commercial banks on China's development agenda, and has made commercial banks an important actor in participating in macroeconomic regulation and control. It emphasizes that finance is the most important in the country and calls for strengthening the governance by the Party on financial sector, showing that the state strengthens the oversight on them. The Communist Party of China (CPC) is built for the public and it exercises state power for the people, which makes the commercial banks perform their social functions well and prevents the dissimilation of their social functions. To prevent real estate bubble, the Chinese government has introduced different policies to limit the purchase of land and real estate according to local conditions. In order to address the issue that commercial banks' inclusive financial services are merely a formality, the Chinese government has also introduced polices for commercial banks to support micro, small and medium-sized enterprises, agriculture and regional economic development, and has imposed severe penalties on banks that violate the provisions of the policy.

\subsection{The essence of socialism is at the heart of everything commercial banks should do}

After the reform and opening-up, the Chinese government has clarified the essence of socialism, pointing out that

"the essence of socialism is to liberate and develop productive forces, eliminate exploitation and polarization, and finally achieve common prosperity" ${ }^{[6]}$, and the essence of socialism is at the heart of everything the government should do. To liberate and develop the productive forces is what the government should do to realize socialism; to eliminate exploitation and polarization, and finally achieve common prosperity is the goal of socialism. Since Chinese commercial bank have been booming with the development of the socialist market economy, it is essential for them to develop socialist commercial banks with Chinese characteristics based on the essence of socialism. Commercial banks actively implement the state regulation policy to ensure the economic and financial security and stable development, maximize their social functions and allocate money and credit resources properly to promote social stability and economic prosperity. They also provide financial assistance for the national infrastructure and livelihood programs, provide inclusive financial services, 
and support micro, small and medium-sized enterprises and programs concerning agriculture rural areas and rural residents. In addition, they make special loans, and commitment to essence of socialism can be reflected in contribution they make to education, health care, charity and other public welfare.

\subsection{Profit-making is seen as the bottom line of commercial banks}

The socialist market economy system in China combines the market economy with the socialist system. Both the role of the market in the allocation of resources and the macroeconomic regulation and control of the state are pivotal. It also focuses on economic development and the balanced and sustainable development in all aspects. After the reform and opening-up, the reform of commercial banks is market-oriented. Under the government's macroeconomic regulation and control, they keep improving their service quality to gain the trust of customers, innovating products and business models to be more competitive in market, updating management mechanisms to improve efficiency, which ultimately keep them growing, from only one bank (the Bank of China) in 1978 with total assets of only 185 billion yuan, to more than 4,600 commercial banks with a total assets of 282,514.6 billion yuan in 2019. ${ }^{[7]}$ Profit-making is the basis for commercial banks to survive and grow. The achievement made by commercial banks not only makes an important contribution to the national finance, but also produces economic benefits for the shareholders, practitioners and major stakeholders of the banks. Furthermore, they have contributed a lot to the development of the banking industry chain, the construction of national infrastructure, the improvement of people's livelihood and the social public welfare undertakings, and more importantly, laid a solid foundation for the sustainable development of China's commercial banks.

\subsection{It is necessary to strengthen the social responsibility of commercial banks}

The Chinese government has strengthened its governance of the social responsibility of commercial banks. In addition to raising awareness of social responsibility in politics, economy, culture, society, resources and environment, it also advocates that idea of serving the people should be reflected in the businesses of commercial banks. Serving the people is the moral core of socialism with Chinese characteristics, around which the moral principle of the collectivism has been built. The Chinese government advocates that commercial banks should strike a balance between the interests of banks and the collective interests, and strive to make profits while accommodating the interests of the state and the people. The difference between Chinese commercial banks and commercial banks in developed capitalist countries in fulfilling their social responsibilities lies in the fact that Chinese commercial banks are committed to serving the people and the purpose of making profits is to serve the people better and provide assistance to the social (collective) civilization and the human development in an all-round manner, while the commercial banks in the developed capitalist countries take the bank capital appreciation as the compass.

\section{Conclusion}

The dissimilation of the social functions of commercial banks is a phenomenon that the function of commercial banks deviates from the economic development and the people's livelihood. Effective prevention and control measures should be taken to maintain the prosperity and stability of social economy and enhance the well-being of the people. Because these banks are profit-driven, such dissimilation can be found all over the world. China has achieved remarkable results in preventing and controlling the dissimilation. Chinese government is people-oriented and clearly defines the social functions of the commercial banks, which are the political guarantee for the continuous and effective functioning of the commercial banks in China. Commitment to the essence of socialism and the good command of law of market economy by Chinese commercial banks are essential to prevent and control the dissimilation of social functions. This is also because commercial banks develop in the socialist market economy in which public ownership is the mainstay, and the government should have experience of helping commercial banks to avoid the dissimilation of the social functions.

\section{References}

[1] Zhuang Yumin. Commercial Banking Business and Operations. Beijing: China Renmin University Press; 2016.

[2] Wang Fengxian. Marxism's Theory of Dissimilation and the Human Development in an All-around Way. Educational Research. 1981; (7): 18-24.

[3] National Bureau of Statistics of China. Bulletin of Statistics on National Economic and Social Development. Available from: http://www.stats.gov.cn/tjsj/ [Accessed 1st June 2020].

[4] Wang Bo. The Essence and Logic of Capital from Marxism, Journal of University of South China (Social Science). 2015; (2): 21-25. 
[5] Website of China Banking Regulatory Commission. Statistics Column. Available from: http://www.cbirc.gov.cn [Accessed 1st June 2020].

[6] Literature Research Office of the CPC Central Committee. Anthology of Deng Xiaoping (Vol. 3). Beijing: People's Publishing House; 2014.

[7] Website of China Banking Regulatory Commission. List of legal persons of banking financial institutions. Available from: http://www.cbirc.gov.cn [Accessed 1st June 2020]. 